\title{
Effective Interventions on Reading Fluency for Students with Learning Disability
}

\author{
Yujia Gao* \\ Xi'an Eurasia University, Xi’an, Shaanxi 710065, China.
}

\section{Introduction}

The purpose of this article is to consider applying some intervention methods to help students with learning disability to improve their reading fluency. It begins by introduce the definition, components as well the importance of reading fluency. Then followed by the review of related literature, introducing research methods, processes and results in detail. Finally, it concludes with discussions and implications about the effective intervention programs.

\section{The definition and importance of reading fluency and its' instruction of students with learning disability}

Reading fluency refers to three levels that includes word, syntactic and passage level ${ }^{[1]}$. And it is also defined as a bridge between the two major components of reading - word decoding and comprehension ${ }^{[2]}$." Teaching and intervention of reading fluency of students with learning disability has become a problem. So the main research problem of this paper is:

What kinds of interventions can be applied to help students with learning disability?

\section{Research done by chard and elias on the research problem.}

(1) Chard's research about effective intervention programs.

In Chard's research, the stress of the intervention program mainly targets at word level and content level of elementary-age students who have learning disabilities. And after yielding 104 related studies, he divided the intervention program into two kinds: repeated reading and word practice interventions with more detailed branches.

In repeated reading part, four models are presented. They are: "repeated reading without a model", "repeated reading with a model", "repeated reading interventions with multiple features", and "other elements that influence fluency performance in

Copyright (C) 2020 Yujia Gao

doi: 10.18282/1-e.v9i4.1722

This is an open-access article distributed under the terms of the Creative Commons Attribution Non-Commercial License (http://creativecommons.org/licenses/by-nc/4.0/), which permits unrestricted non-commercial use, distribution, and reproduction in any medium, provided the original work is properly cited.

Village, Song Jiang's idea of "killing Zhujia Village" and so on. This is of course the negative side of "swordsman" of heroes, but as mentioned above, chivalrous men often take safeguarding their personal moral interests as the yardstick. They are used to dividing the non-self-moral into hostile forces. Wu Song spared no effort to "be happy, love and revenge", Li Kui for the sake of brotherhood morality and freedom, and Song Jiang for the sake of village spirit and reputation. This can also be regarded as a manifestation of the agitation of "swordsman and Confucianism" in Outlaws of the Marsh, but it still takes "Confucianism" as its core.

\section{Confucianism inside and swordsman outside in the "Outlaws of the Marsh" world}

To sum up, the relationship between "swordsmen culture" and "Confucian culture" contained in Outlaws of the Marsh should be based on "Confucianism" inside and "swordsmen" outside. In other words, "Confucianism" is the spiritual core of "Outlaws of the Marsh" and "swordsman" is its behavior choice. Whether it is the purpose of the organization or the concept of the activity, it fully reflects this point. Of course, this "Confucianism" is not the "benevolence" and "self-denial and restoration of rites" of Confucianism's classics, but the loyalty to the imperial power emphasized by Neo-Confucianism in Song and Ming Dynasties. "swordsman" is the man of Jiang-hu divided by Han Yuanbo.

\section{References}

[1]Sima Qian. Records of the Historian[M]. Beijing: China Publishing House, 1959.

[2]Han Yunbo. On the basic characteristics of Chinese chivalrous culture[J]. Journal of Southwest Normal University (Philosophy and Social Sciences), 1993; (1): 104-110.

[3]Shen Yuwen, Sha Jingjing. Development and Contemporary Significance of Neo-Confucianism in Song and Ming Dynasties[J]. Anhui literature, 2008; (7): 373-374. 
repeated reading interventions ${ }^{[3]}$." In repeated reading without a model, target students are asked to read a text without guidance, for more than two times and the maximum is seven times. Among the researches that focus on this area, researcher including Smith find that the mean effect size of this on affecting students reading fluency is $\mathrm{d}=1.98$ and students can perform much better ${ }^{[4]}$. With a model, students are showed how to read a text. Results show that students can give back surprising results. Also, helpers' feedback works.

In word practice interventions, a word drill procedure is compared with a phrase drill procedure, using flash cards to present missing words from an initial oral reading baseline phase. In phrase drill condition, students are given the opportunity to practice error words in context that helps them more.

To sum up, several interventions can be regarded effective to help students who have leading disability build and improve their reading fluency. The interventions includes give those students a fluent reading model while they are doing reading. And when they read repeatedly, various chances should be given to let them independently read the text that they are familiar with. During this procedure, people provide the fluent reading model should give feedback to help them get correct version of the reading. Finally, established performance criterion is needed in increasing the text difficulty according to readers' learning ability.

(2) Elias's study about the effectiveness of an intervention program of students with more specific learning disability.

In Elias's study, the author mainly focuses on discussing whether an intervention program called Barton intervention program is effective in helping students with dyslexia improve their reading motivation as well as reading fluency. The students selected are also elementary-age students, but the targets are more strictly controlled since all the students are coming from fourth and fifth grade with one kind of learning disability - dyslexia.

In the study, dyslexia is regarded as "an unusual type of severe reading disability that has puzzled the educational and medical communities for many years ${ }^{[5]}$." And it is unexpected, affecting large amount of people (over $80 \%$ ) with learning disability ${ }^{[6]}$. And it causes a decreasing trend of students' reading performance. Students with this kind of learning disability have various problems in reading and perform not as well as others of the same age in standardized tests.

. Students with this perform not as well as others of the same age. Finally, 138 eligible students are selected. Among them, 2 groups are divided - the experimental and the control group. For the experimental one, Barton program lasts for 3 months while the control group did not perform the Patton plan. It focuses on the mature and effective guidance.

Then students with learning disability do a test to see their ability to read fluently with speed and accuracy. And the difficulty of the texts is gradually increasing. Students have to decide whether the statements about the text are correct or not. It measures not only reading speed, but also accuracy.

Finally, data show experimental group are higher than the control group and Barton Intervention Program is quite effective and it can be a good supplement of traditional ones.

\section{Discussion and implication}

The two studies, to a large extent, can answer the research question of this paper but there are still have some limitations left.

Both the two researches strictly chose target students and all of them can satisfy the needs of the study in this paper. And the research procedures are scientific with the support of several literature of famous scholars and data computed by computers. Besides, validity and reliability of the measures are high. From the two researches, we know that repeated reading is essential in improving those students reading fluency. And students will get more familiar with the test and then read with faster speed and better accuracy. And reading with model is better.

However, there are also some problems that are still not solved. Since my research question is mainly focus on the intervention of students with learning disability, the interventions mentioned in the two studies are quite similar to the interventions of reading fluency for normal students. Since students with learning disability are different from normal students, they face more challenges and difficulties in learning and reading. Take students with dyslexia as an example, they faces problems in word recognition as well as passage reading and cannot focus on what they read. Compared to normal students, they should be given more practice aiming at overcoming their shortcomings. Repeated reading is a good way, but what is the difference between using it as an intervention to normal students and to students with learning disability.

Lastly, since students with learning disability, especially with dyslexia, always cannot focus on one thing for too long. Further studies are still needed to answer the research question in the paper.

\section{Reference}

[1]LaBerge, D., \& Samuels, S. J. (1974). Toward a theory of automatic information processing in reading. Cognitive psychology, 6(2), 293-323.

[2] Rasinski, T. V. (2004). Assessing reading fluency. Regional Educational Laboratory at Pacific Resources for Education and Learning.

[3] Chard, D. J., Vaughn, S., \& Tyler, B. J. (2002). A synthesis of research on effective interventions for build reading fluency with elementary students with learning disabilities. Journal of learning disabilities, 35(5), 386-406.

[4] Smith, D. D. (1979). The improvement of children's oral reading through the use of teacher modeling. Journal of Learning Disabilities, 12, 172-175.

[5] Elias, H., Nor, S., \& Mahmud R. (2011). The Effectiveness of the Intervention Program on Reading Fluency and Reading Motivation of Students with Dyslexia. Asian Social Science, 7(3), 187-199.

[6] Lerner, J. (2006). Learning disabilities and related disorders, characteristics and teaching strategies. Boston: Houghton Mifflin Company. 